\title{
A novel treatment approach for common carotid artery bifurcation aneurysms
}

\author{
Efe Edem, Ersan Tatli, Mehmet Bülent Vatan, Saadet Demirtaş, Mehmet Akif Cakar, Harun Kilic \\ Sakarya University Training and Research Hospital, Sakarya, Turkey
}

Postep Kardiol Inter 2015; 11, 4 (42): 349-350

DOI: $10.5114 /$ pwki.2015.55612

\section{Introduction}

An aneurysm involved in common carotid artery (CCA) bifurcation is a rare clinical condition. There are not enough natural follow-up data, and there is no evidence-based treatment algorithm [1]. An endovascular approach is used to treat CCA bifurcation aneurysms, as it offers some advantages in selected patient populations; nonetheless, closure of the aneurysmal segment in CCA bifurcation using a graft stent has some challenges, mainly occluding the ostial part of the external carotid artery (ECA). Coil embolization of a CCA bifurcation aneurysm is preferred over graft stent implantation in this condition; however, coil embolization cannot provide appropriate treatment in patients suffering from a CCA bifurcation aneurysm with significant stenosis in the proximal part of the internal carotid artery (ICA).

Herein, we present a male patient whose CCA bifurcation aneurysm with significant stenosis in the proximal part of the ipsilateral ICA was successfully treated with the implantation of two nested self-expandable closedcell stents.

\section{Case report}

A 54-year-old hypertensive male patient was admitted to our clinic due to recurrent episodes of transient ischemic attack in the last 3 months. His carotid angiography revealed a right-sided CCA bifurcation aneurysm with $50-60 \%$ stenosis in the proximal part of the ICA (Figure $1 \mathrm{~A}$ ). Due to the possibility of occluding the ostial part of the right ECA if we close the aneurysmal segment with a graft stent, we preferred to close the aneurysmal segment by implanting two nested self-expandable closedcell stents. The patient had already been on $100 \mathrm{mg} /$ day aspirin for 2 months and received a $300 \mathrm{mg}$ loading dose of clopidogrel the day before the procedure. A written informed consent form was provided before the procedure.
A $40 \times 8-6 \mathrm{~mm}$ Xact stent (Abbott Vascular, USA) was implanted successfully after the Emboshield NAV6 Embolic Protection System (Abbott Vascular, USA) had been placed distally to the target lesion (Figure $1 \mathrm{~B}$ ). However, we observed that the CCA bifurcation aneurysm persisted after stent implantation (Figure $1 \mathrm{C}$ ). Therefore, a $30 \times 7 \mathrm{~mm}$ Xact stent (Abbott Vascular, USA) was implanted inside the first stent. The final carotid injection showed that the aneurysm was substantially closed (Figure $1 \mathrm{D}$ ). After the procedure, a combination of clopidogrel $75 \mathrm{mg} /$ day and aspirin $100 \mathrm{mg} /$ day was planned for 2 months and aspirin $100 \mathrm{mg} /$ day indefinitely. The patient was scheduled for control CT angiography 3 months later to check the stent appositions, the patency of the vessel and the exclusion of the aneurysm.

\section{Discussion}

There are limited data available in the literature about the optimal treatment method of CCA bifurcation aneurysms. Recently, Welleweerd et al. started a registry to address diagnostic and therapeutic questions about the management of extracranial carotid artery aneurysms [1]. Alternative treatment options other than surgical resection, mainly endovascular treatment, have been debated in the last few years [2, 3]. Due to the concomitance of significant stenosis in the proximal part of the ICA with a CCA bifurcation aneurysm and the unsuitability of closing it with a graft stent, in this case we treated the CCA bifurcation aneurysm with the implantation of two nested self-expandable closed-cell stents. The final carotid injection showed a satisfactory result.

\section{Conclusions}

Coil embolization of CCA bifurcation aneurysms cannot provide sufficient treatment in patients suffering from a CCA bifurcation aneurysm with significant steno- 
A
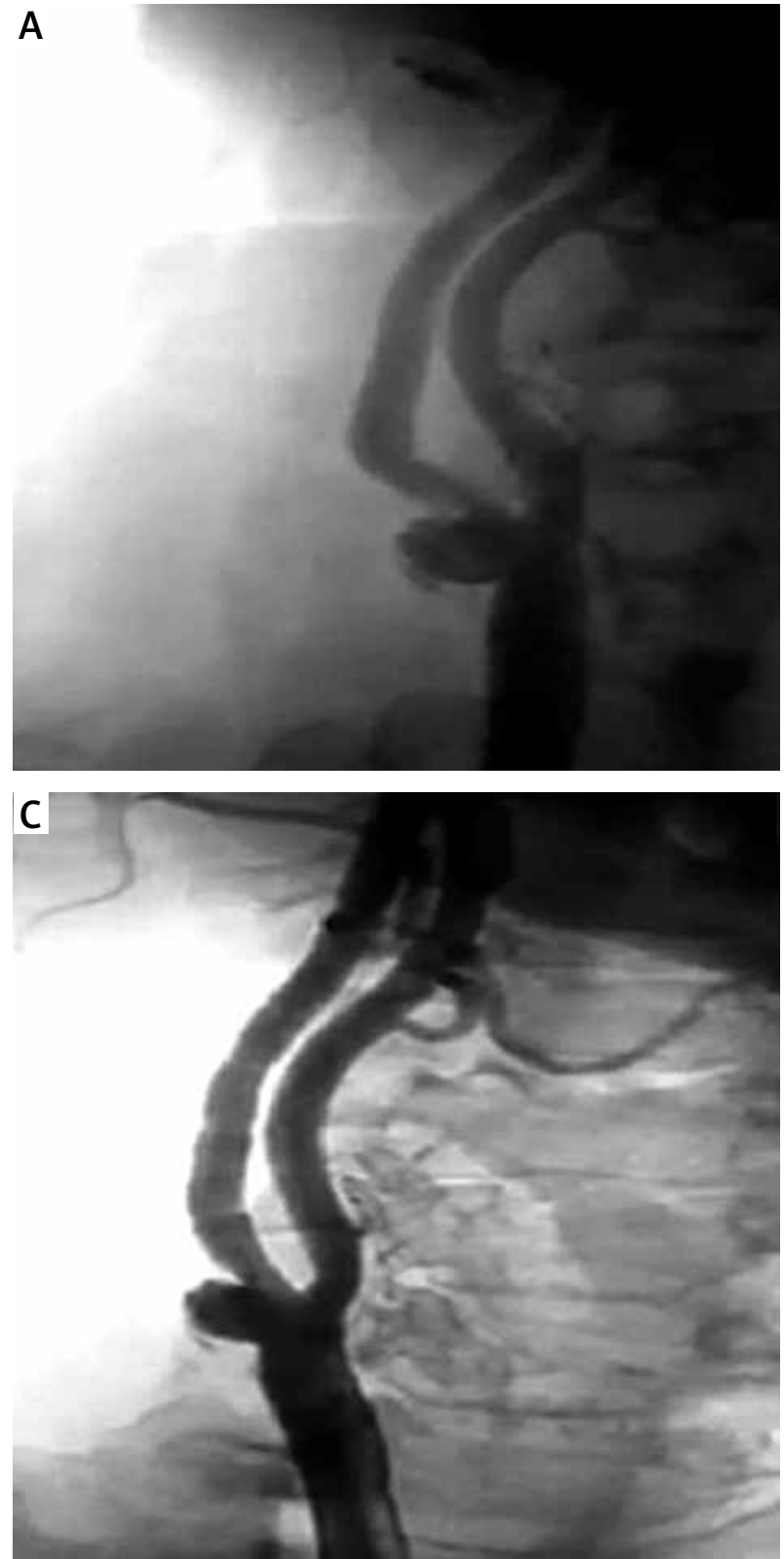
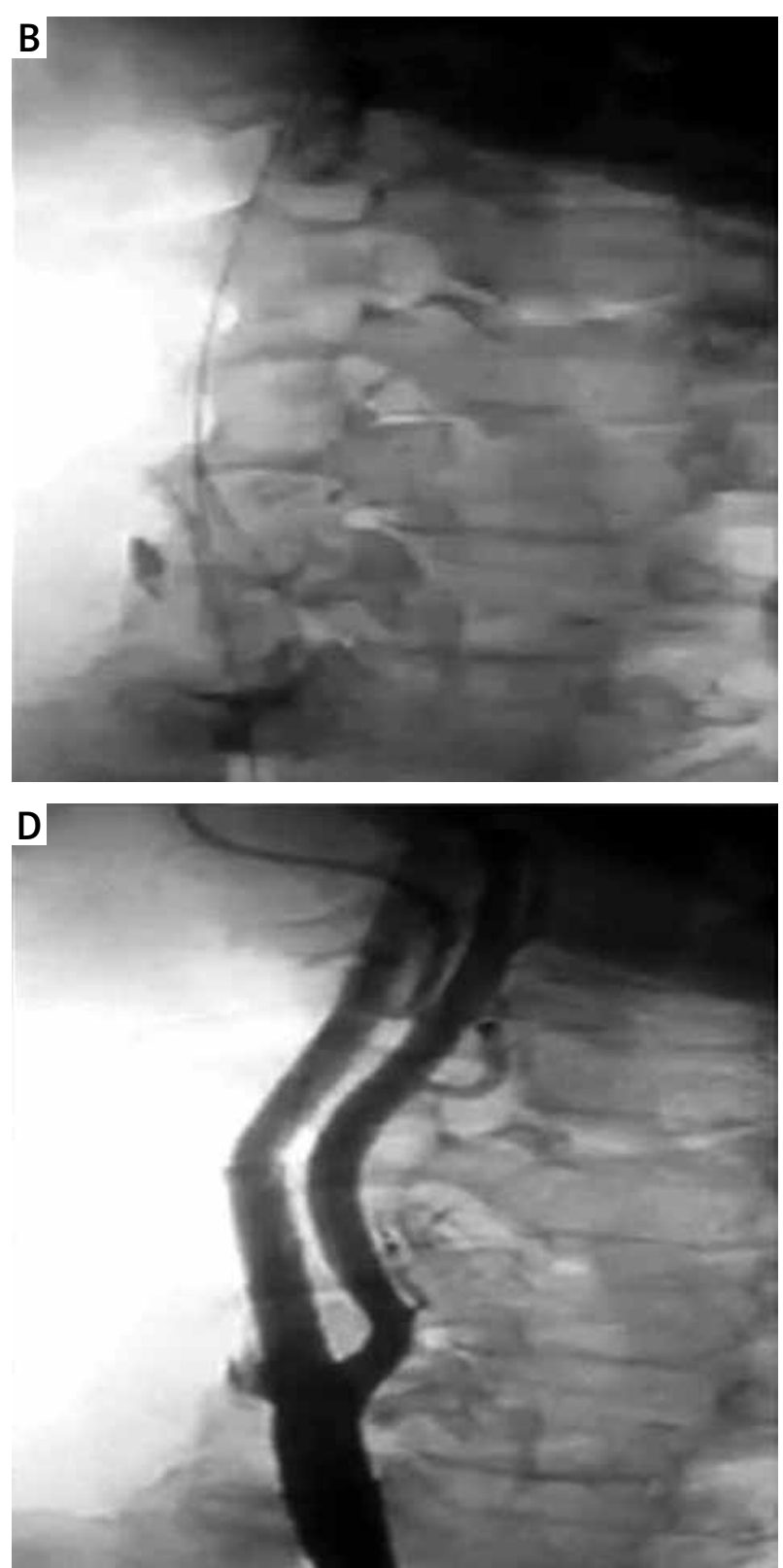

Figure 1. A - Angiographic view of a right-sided common carotid artery (CCA) bifurcation aneurysm with 50-60\% stenosis in the proximal part of the internal carotid artery (ICA). B - Deployment of the first Xact (Abbott Vascular, USA) self-expandable closed-cell stent. C - Persistence of the CCA aneurysm after implantation of the first stent. D - Final carotid injection showing substantial closure of the CCA bifurcation aneurysm after deployment of the second Xact (Abbott Vascular, USA) self-expandable closed-cell stent

sis in the proximal part of the ipsilateral ICA. Therefore, we suggest deploying two nested self-expandable closedcell stents as an alternative method for the treatment of CCA bifurcation aneurysms, particularly if accompanied by significant stenosis in the proximal part of the ipsilateral ICA.

\section{Conflict of interest}

The authors declare no conflict of interest.

\section{References}

1. Welleweerd JC, Bots ML, Kappelle LJ, et al. Rationale and design of the extracranial carotid artery aneurysm registry. J Cardiovasc Surg (Torino) 2015 Feb 6 [Epub ahead of print].

2. Welleweerd JC, Moll FL, de Borst GJ. Technical options for the treatment of extracranial carotid aneurysms. Expert Rev Cardiovasc Ther 2012; 10: 925-31.

3. Welleweerd JC, de Borst GJ. The Carotid Aneurysm Registry Project Group. Extracranial carotid artery aneurysm: optimal treatment approach. Eur J Vasc Endovasc Surg 2014 Dec 9. pii: S1078-5884(14)00634-0. 